\title{
CRISIS PSYCHODRAMA IN THE ERA OF COVID-19
}

\author{
Aleksandra Mindoljević Drakulić \& Vivijana Radman \\ Faculty of Humanities and Social Sciences, University of Zagreb, Zagreb, Croatia
}

received: 7.4.2020;

revised: 9.4.2020;

accepted: 10.4 .2020

\section{SUMMARY}

This work gives an overview of the methods of scenic expression which can be used to help cope with the crisis caused by the global threat of the coronavirus pandemic. The virus is new, the vaccine has not been developed yet and there are no unified prevention and post-prevention policies. In the following lines some modified elements of psychodrama interventions are presented including the ways of preventing the retraumatization of the patient (protagonist). This can be achieved by conscious reliving of the trauma and by activating new, transformative roles to guide the protagonist on his way to recovery.

Key words: psychodrama interventions - COVID-19 - coronavirus - role theory

$$
* * * * *
$$

\section{INTRODUCTION}

While Sigmund Freud, the founder of psychoanalysis, studied trauma in the individual and family setting and explained it intrapersonally, that is, via the manifestation of the intrapsychic conflict, Jakob Levy Moreno, the founder of psychodrama, studied the trauma interpersonally, in the wider context of his work with groups and the society as a whole.

There has been a great number of clinical studies published worldwide proving the usefulness and effectiveness of the classical psychodrama as a treatment for a variety of traumatic experiences (Baumgartner 1986, Blatner 1997, Kellermann 1992, Kipper 1989, Mindoljević Drakulić 2011). Even if the field of trau$\mathrm{ma}$ is vast (from natural disasters to disruptive social changes) this article treats the way psychodrama therapy can deal with the trauma caused by the Covid-19 pandemic. Coronavirus was first discovered in China by the end of 2019. Although it was originally found in animals, it now spreads relatively quickly and easily from person to person. It causes flu-like symptoms, in severe cases pneumonia and acute respiratory distress syndrome, and in the most severe cases sepsis, septic shock and death (Thirumalaisamy \& Meyer 2020, Croatian Institute of Public Health 2020).

The present of the Covid-19 pandemic we currently live in plus the post-pandemic future of the inevitable recession, suggest that a part of the global population would certainly need some form of psychotherapeutic counseling and/or help.

This was first established in China; authors Duan and Zhu state that this densely populated state has an absolutely insufficient number of mental health workers trained to provide psychological assistance to the Chinese during and after the pandemic (Duan \& Zhu 2020). In addition, as stated by A. Flahault of the University of Geneva, general cacophony and misinformation regarding coronavirus prevention are ongoing, further contributing to the global insecurity (Flahault 2020).
The sense of confidence in the aid system has been put to a great test by this crisis (Atlani-Duault et al. 2020). Being aware that the extreme social changes will result from the coronavirus pandemic and that these changes will be reflected in the ways people will be living their lives makes this all the more important. Further, the problems of social isolation and loneliness in the situation of social distancing will increase the risk of anxiety disorders, depression, aggressiveness, the use of psychoactive substances and addiction disorders, which will further influence the appearance of a number of psychosomatic diseases like asthma, obesity, diabetes, heart conditions etc (Brooke \& Jackson 2020).

Because the classical psychodrama has been developed from a number of psychotherapeutic schools, behaviorism (role repertoire, affect regulation, behavioral training, etc.) and psychoanalysis (the concepts of transference and countertransference, the unconscious and the conscious, the defense mechanisms etc.) (Mindoljević Drakulić 2014) in particular, this work focuses on the theoretical aspects of the so called crisis psychodrama which rely on this eclectic approach. One such comprehensive and unique approach which begins from the experiences of the traumatized is the Therapeutic Spiral Model - TSM developed by the American psychodramatist and clinical psychologist Kate Hudgins (Hudgins 2002).

\section{EXPERIENTAL PSYCHOTHERAPY AND ROLES}

TSM is an action method of the experiential management of the therapeutic process involving a variety modified elements of interventions, while, simultaneously, ensuring the prevention of the uncontrolled regression and retraumatization of the patient (protagonist). This is achieved by applying the principles of the conscious reliving of trauma, in order to safely guide a person's transformation from a victim role.

Persons psychotraumatized by a crisis, including those traumatized by the events resulting from the pandemic, 
are inclined to abreact, that is, to act out in reaction, meaning that their powers of verbalization are significantly diminished. Because they have a certain word deficit, psychodrama TSM seems to be one of the possible psychotherapeutic procedures for such persons. In order to help the protagonist, this model is described using the graphic representation of the spirals. Pictorially, the image of the spiral reminds the protagonist of the existence of the uncontrolled energy of the trauma, which, like the uncontrolled energy of the tornado, crashes everything in its way. In the TSM model, the protagonist needs to learn how to move along the spiral without being blown away by the chaos of the tornado. Spirals are, therefore, symbols for the protagonist to use to organize traumatic experience in the words he can understand.

There are three strands of the spiral used to depict the internal representation of the trauma for the protagonist. Healthy functioning means that a person freely moves along the three strands, but, after a trauma, the movement along the strands of the spiral can become restricted, distorted or completely blocked. The first strand is the energy strand. It is defined as a state of creativity, spontaneity and the vitality of a person. One can approach it through a number of roles a person plays: family roles, racial roles, cultural roles, etc. For example, one of the protagonist's roles could be that he is a father, but, during the Covid-19 pandemic he might not be able to see his child due to the quarantine.

The second strand is the strand of experience; here the emphasis is on the protagonist becoming aware of all of his experiences without him becoming overwhelmed by the sensations. For example, the protagonist who doesn't feel well during the period of the quarantine could say: ,help me to climb the spiral, so that I could feel less and think more".

The third strand is the strand of meaning. It shows that people live their lives in accordance with the meanings resulting from previous (developmental) experiences. For example, a protagonist is having an exceptionally hard time being quarantined, and has increasing difficulty enduring it, as it reminds him of the periods in early childhood when he was left without his mother. In psychodrama the protagonist must become aware of this transfer and learn new roles so that during the quarantine he can behave as the situation demands, that is, as an adult.

In order to better understand the trauma, it is exceptionally important to find adequate words, that is, to describe every detail of what happened to the traumatized self. These words and explanations are, in TSM, represented by the so called trauma bubbles used to describe systematic changes in consciousness as a result of traumatization. Unfortunately, the bubbles can burst and all of the past traumatic material can overwhelm the protagonist again in the present. In spite of this, the existence of the bubbles allows the protagonist to communicate with them, which, actually, constitutes the starting point of taking the control of the unprocessed traumatic image.

For example, the protagonist in the psychodrama describes the bubble in which he is taken to the hospital.
In the next bubble he describes the gasps of catching his breath in the hospital. In the third bubble there are the nurses ignoring his requests, etc. Since all of the experiences from the bubbles are dislocated from the conscious part of the protagonist's mind, they can be seen as the scattered graphic images allowing the protagonist to better understand the complexity of his trauma.

Except for the three strands of the spiral, there is also the so called social atom of the traumatized protagonist. It is a map of the protagonist's basic life roles which can be classified as prescriptive roles, trauma based roles and transformative roles.

The function of the prescriptive roles is to prevent retraumatization and they can be: restoration roles (for example the therapist suggests to the protagonist, just before he is to face the moment of going to the hospital, to pick a member of the psychotherapy group to stand by him for the duration of leaving the house), observation roles (for example, the protagonist picks a member of the psychotherapy group to become emotionally detached observer who will collect facts and become the so called witness to the events on the so called stage with the task of recording the details of the traumatic event) and the containment roles (for example, the protagonist picks a member of the psychotherapy group as his double to stand by his side, empathize with him and identify with the protagonist's role by saying the lines and using the body language that will evoke positive emotions and create the sense of security in the protagonist).

These three roles prevent the retraumatization, motivate the protagonist to remain aware of his feelings (which is particularly important in dissociation) and return to the protagonist the sense of control over past, over the situation in which he felt confined and captive, which, in the long term, secures more efficient reparation.

Trauma based roles can be linked to the primitive defense mechanisms a person utilizes to survive the traumatic experience (for example, protagonist is having a hard time during the scene, so he starts to dissociate, and the leader of the psychodrama suggests to him to pick a member of the psychodrama group to whom the dissociation role is given, so the protagonist can, in the following scenes, remove him from the psychodrama stage, etc.). They can, alternatively, be linked to the authorities who/which failed at timely reaction of saving the protagonist (for example, such role can be changed, that is, understood as a part of the reorganization of the protagonist's self, allowing him to, with the help of one or more members of the group, create an authority who/ which will save the day/provide support/provide the protagonist with something he didn't get in reality etc.)

When the prescriptive roles and the trauma based roles are played on the psychodrama stage new creative energy is created in action and new, transformative roles appear for the protagonist to play. The protagonist utilizes these roles in the establishment of his own autonomy as well as for developing a greater sense of connection/ integration with himself and others. This is a very important moment in the psychodrama work, because the 
protagonist creates a new, unique, personalized role to help him repair the painful experience in a new and different way (Kellermann 2002).

\section{CREATING RECOVERY ORIENTED ROLE}

In this way the protagonist (by acquiring new experiences of socialization and by articulating internal and external reality) learns how to change his behavior which results in the changed response of his environment. Marija Čiček, a Croatian psychiatrist terms this "experimenting with the creation of object distance" (Čiček 1987).

American psychodramatist Tian Dayton stresses the importance of securing the space for the exploration of and working through the new and undeveloped protagonist roles in psychodrama sessions. This she achieves in three ways: first, it is important to secure a space for the protagonist to practice playing the new role in psychodrama, so that he can adapt to it; second, it is important to see if the role fits the protagonist; third, it is important to be ready to explore the role from the personal perspective and the perspective of the significant other, which is the basis of the psychodrama work. Psychodramatist T. Dayton calls this type of work "recovery oriented role" emphasizing the importance of the integrative, behavioral and psychodynamic approach (Dayton 2003).

When we talk about roles in psychodrama, we usually refer to the group type of psychotherapeutic work. But, in the situation of social distancing during and after the pandemic, it is and it will be very important to understand, accept and adapt to the adequate psychodrama models primarily intended for the individual setting. For example, instead of the initial warm-up as it is done in psychodrama group, in the individual setting one can apply psychodrama interventions, like free association, which can also lead to action. Further, the extremely important issue of touching in psychodrama becomes even more complex in the individual setting due to the dimension of transfer in the therapeutic relationship. This, for example, means that since the role of the containing double in the individual setting can't be played by another person, the protagonist could be offered a variety of psychodrama props (pillows, puppets, balls, blankets, scarves and such) instead (Chesner 2019).

\section{CONCLUSIONS}

To conclude, even if technically challenging and requiring a psychotherapist trained both in psychodrama and psychodynamic approach, the described therapeutic spiral model can be a treatment of choice for the persons traumatized by the consequences of Covid-19 epidemic. However, it should be adapted to psychodrama interventions characteristic for the individual setting. The treatment of such trauma requires a psychotherapist with a high ability for containment and involves a number of diverse, often eclectic interventions, which in the language of the role theory means substituting the lost relationship with another internalized role.

\section{Acknowledgements: None.}

Conflict of interest: None to declare.

\section{Contribution of individual authors:}

Aleksandra Midoljević: idea, concept and design of the article, writing manuscript, approval of the final version.

Vivijana Radman: concept and design of the article, approval of the final version.

\section{References}

1. Atlani-Duault L, Ward JK, Roy M, Morin C, Wilson A: Tracking online heroisation and blame in epidemics. The Lancet 2020; 5:137

2. Brooke J, Jackson D: Older people and Covid-19: Isolation, risk and ageism. J Clin Nurs, In press; 2020

3. Chesner A: One-to one psychodrama: applications and techniques. Routledge, London-New York, 2019

4. Croatian Institute of Public Health: Retrieved from www.hzjz.hr, April 6th, 2020

5. Čiček M: Doprinos istraživanju individualne psihoterapije scenskom ekspresijom u liječenju poremećaja identiteta adolescenta. PhD Dissertation, School of Medicine Zagreb, 1987

6. Dayton T: Psychodrama and the treatment of addiction and trauma in women. In Gershoni J. (ed): Psychodrama in the 21 century: Clinical and educational applications, 175-195. Springer Publishing Company; New York, 2003

7. Duan L\& Zhu G: Psychological interventions for people affected by the COVID-19 epidemic. The Lancet 2020; 7:300-302

8. Flahault A: COVID-19 cacophony: is there any orchestra conductor? The Lancet 2020; 395:1037

9. Hudgins MK: Experiental treatment for PTSD - The Therapeutic Spiral Model. Springer Publishing Company, New York, 2002

10. Kellermann PF: Sociodrama and collective trauma. Jessica Kingsley Publishing, London - Philadelphia, 2007

11. Mindoljević Drakulić A: Critical reflections for understanding the complexity of psychodramatic theory. Psychiatr Danub 2014; 26:12-19

12. Thirumalaisamy PV, Meyer CG: The COVID-19 epidemic. Trop Med Int Health 2020; 5:278-280

\section{Correspondence:}

Aleksandra Mindoljević Drakulić, PhD

Faculty of Humanities and Social Sciences

Lučićeva 3, 10000 Zagreb, Croatia

E-mail:aleksandra.mindoljevic@gmail.com 